\title{
Impact of risk factors on prevalence of anal HPV infection in women with simultaneous cervical lesion
}

\author{
J. SLAMA ${ }^{1, *}$, B. SEHNAL ${ }^{2}$, L. DUSEK ${ }^{3}$, T. ZIMA ${ }^{4}$, D. CIBULA ${ }^{1}$
}

${ }^{1}$ Gynecologic Oncology Centre, $1{ }^{\text {st }}$ Faculty of Medicine, Charles University and General University Hospital in Prague, Czech Republic; ${ }^{2}$ Gynecologic Oncology Centre, $1^{\text {st }}$ Faculty of Medicine, Charles University and Hospital Na Bulovce, Prague, Czech Republic; ${ }^{3}$ Institute of Biostatistics and Analyses, Masaryk University, Brno, Czech Republic; ${ }^{4}$ Institute of Clinical Biochemistry and Laboratory Diagnostics, $1^{\text {st }}$ Faculty of Medicine, Charles University and General University Hospital in Prague, Czech Republic

${ }^{*}$ Correspondence: Jiri.Slama@vfn.cz

Received May 3, 2014 / Accepted August 25, 2014

\begin{abstract}
The aim of our study was to determine the risk factors associated with anal HPV infection in HIV-negative women with high-grade cervical lesion. The study group included 172 "high-risk" women who underwent conization for high-grade cervical intraepithelial lesion or microinvasive cervical cancer (CIN 2+). The control group consisted of 100 "low-risk" women with non-neoplastic gynecologic diseases. All participants completed a questionnaire detailing medical history and sexual risk factors and were subjected to anal and cervical HPV genotyping. Concurrent cervical and anal HPV infections were detected in $42.4 \%$ (73/172) women of the study group, and in $8.0 \%(8 / 100)$ of women in the control group, respectively. The subgroup with concurrent HPV infections $(n=73)$ dominated women with CIN 3 and microinvasive cancer and anal HPV 16 infections $(n=53)$. Women with concurrent infections more frequently reported any type of sexual contact with the anus including non-penetrative anal sex (OR 2.62, p=0.008). Reporting $>5$ lifetime sexual partners (OR 2.43, p=0.041), smoking $>60$ cigarettes per week (OR 2.33, p=0.048), and a history of penetrative anal intercourse (OR 3.87, $\mathrm{p}=0.002$ ) were observed as the significant risk factors in women with multiple concurrent HPV infections. Our data support anal HPV testing and anal Pap smear screening in all women with severe cervical lesions caused by HPV 16 and a history of any sexual contact with the anus, heavy smoking and/or more than 5 lifetime sexual partners.
\end{abstract}

Key words: anal cancer, cervical intraepithelial neoplasia, HPV, risk factor

Anal cancer is an uncommon disease, but its incidence has grown during the last decades in most developed countries [1]. The population at the highest risk of developing anal cancer includes HIV-infected subjects, males who have sex with males and transplant recipients [2-6]. Despite this fact, a still significant proportion of anal cancers are detected in generally healthy and HIV-negative subjects. Moreover, anal cancers are more frequently detected in women than in men [7]. In the U.S., invasive anal squamous cell carcinoma rates increased among females by $1.7 \%$ per year between 1973 and 2005 [1]. In 2012 there were an estimated 6230 new cases of anal cancer in the U.S., with 3980 (63.9\%) cases occurring in women and only 2250 (36.1\%) cases in men [8]. Similarly, in the Czech Republic the prevalence of anal cancer is constantly higher among women than in men. In 2010 there were 129 new cases of anal cancer, with $85(65.9 \%)$ cases in women and $44(34.1 \%)$ cases in men.

This gender difference is not clearly explained. Since more than $90 \%$ of anal cancers are caused by high-risk human papillomavirus (HR HPV) infection [9], possible reasons for the greater risk in women include history of cervical intraepithelial neoplasia (CIN) and cervical cancer [10-12]. The only two studies dealing with women with lower genital tract intraepithelial lesions or cancers which also looked at anal HPV showed 45 $51 \%$ HPV prevalence in this group $[13,14]$. In contrast, a large study on the prevalence of anal HPV infection in a healthy population demonstrated just $13 \%$ (178/1363) of cases with concurrent anal and cervical HPV infection [15].

Although the prevalence of anal HPV infection is significantly higher in women with CIN than in generally healthy 
women, it is still necessary to better define the subgroup of women with the highest risk of subsequent anal cancer, which could be candidates for anal cancer screening. The aim of our prospective study was therefore to evaluate potential risk factors for development of anal HPV infection within the group of patiens with high-grade cervical lesions.

\section{Patients and methods}

Patients. Participants were recruited in the period between September 2011 and June 2012 from women over 18 years of age attending an university-based Colposcopy clinic. The study cohort included "high-risk" patients in whom CIN 2, CIN 3, adenocarcinoma in situ (AIS) or microinvasive cancer was confirmed by conization. The control group consisted of "low-risk" (LR) patients with diverse non-neoplastic gynecological diagnoses (irregular bleeding, endometrial polyp, missed abortion and induced abortion). In the control group, a history of biopsy-confirmed CIN 1 with subsequent normal Pap smears was not exclusion criterion as transient HPVassociated lesions are common in general population. Patients with any other sexually transmitted diseases were excluded. Risk factors affecting immune system response on HPV infection or having influence on prevalence of HPV in genitoanal area were assesed. All participants completed an anonymous self-administered questionnaire on their medical histories (including tobacco use, autoimmune diseases and personal or partner's presence of condylomata acuminata), reproductive histories (gravidity, parity, form of contraception, use of hormonal therapy), sexual behavior (age of sexual debut, lifetime number of partners, frequncy of non-penetrative (finger, oral or skin-to-skin) contact with the anus, practicing of anal intercourse), and social status. They were familiarized with the study protocol and signed an informed consent. The study had been approved by the Ethical Committee of $1^{\text {st }}$ Faculty of Medicine, Charles University.

HPV detection and genotyping. Trained clinicians obtained exfoliated cervical and anal cell samples for HPV detection. A brush was used to smear the entire ectocervix and endocervix, including the entire transformation zone and anal transformation zone. Following the cervical specimen collection, an exfoliated anal cell specimen was obtained using another brush inserted $\sim 1.5$ to $2.0 \mathrm{~cm}$ into the anus and rotated $360^{\circ}$ clockwise ( 3 times) and counter-clockwise (3 times). Each sample was taken separately into the PreservCyt transport medium with maximal care being exercised to prevent contamination. The Linear Array Genotyping HPV test was used for all samples as described by kit manufacturer (Roche Molecular Systems, Inc., Branchburg, NJ). The Linear Array Genotyping HPV test was performed to identify 37 HPV genotypes that included 13 high-risk (HPV 16, 18, 31, $33,35,39,45,51,52,56,58,59$ and 68 ) and 24 low-risk types (HPV 6, 11, 26, 40, 42, 53, 54, 55, 61, 62, 64, 66, 67, 69, 70, $71,72,73,81,82,83,84$, IS39 and CP6108). The strips were manually interpreted using the Linear Array HPV reference guide, by reading the individual types down the length of the strip.

Histopathology. All biopsy specimens submitted for histological assessment were routinely examined. Sections from the formalin-fixed and paraffin-embedded tissue fragments were stained with hematoxylin-eosin. Histological grading of dysplasia was based on the standard CIN 1, CIN 2 and CIN 3 criteria.

Statistical analysis. Standard robust summary statistics were applied to describe primary data, absolute and relative frequencies for categorical variables and median supplied with $5^{\text {th }}-95^{\text {th }}$ percentile range for continuous variables. Statistical significance of differences between the "low-risk" group and the group of CIN 2+ patients in categorical variables was tested using the Fisher exact test; an exact Monte Carlo method with 100000 samples was applied to estimate the significance of differences in variables with more than two categories. A Mann-Whitney U test was applied to test the differences in continuous variables. Multiple logistic regression models with age as covariate factor was used to get age-adjusted estimates of any associations between various risk factors and defined end-points related to different types of HPV infection. The results are represented as estimates of odd ratios (OR, along with $95 \%$ confidence interval) with corresponding statistical significance (Wald's test). Concordance of HPV genotype profiles between cervical and anal infections was analysed using Jaccard's coefficient which belongs to a group of asymmetric binary coefficients of similarity. All analyses were performed using SPSS 20.0.0. (IBM Corporation, Armonk, NY, USA, 2011).

\section{Results}

In total, 272 patients were included in the study, 172 patients in the study group and 100 women in the control group, which included 19 patients with a history of CIN 1 and 91 women without any previous or current cervical lesion. Characteristics of both cohorts are summarised in table 1. The population was racially and ethnically homogeneous, with comparable age and social status.

Anal HPV infection was detected in 92 women (53.5\%) from the study group and in $28(28.0 \%)$ women from the control group $(P<0.001)$. Simultaneous HPV infection of the cervix and anus was confirmed in $42.4 \%$ (73/172) of women from the study group while only in $8 \%(8 / 100)$ of patients from the control group. Multiple anal HPV infection was found only in women from the study group $(16.9 \% ; 29 / 172)$. The prevalence of anal HPV infection differred in subgroups with different histological result and it significantly increased with the grade of cervical lesion. In the subgroup with no history of cervical lesion was detected in $18.5 \%$ patients $(15 / 81)$, in the subgroup with a history of CIN 1 in $31.6 \%(6 / 19)$, in patients with CIN 2 in $37.7 \%(23 / 61)$, in patients with CIN 3 in $48.5 \%$ (48/99) and in patients with microinvasive cervical cancer in $55.5 \%(5 / 9)$. 
The prevalence of anal LR HPV infection did not differ between groups. Significantly different results were, however, obtained in HR and combined (LR and HR genotypes together) HPV anal infections. Single HR HPV anal infection was detected in 34 subjects (19.8\%) of the study group and in 10 women $(10 \%)$ of the control group $(P=0.034)$. The prevalence of combined anal infection was significantly more frequent in the study group $(29 / 172 ; 16.9 \%)$ than in the control group 4/100; 4\%; $P<0.001$ ). The occurrence of genotype HPV 16 was unambiguously dominant in all groups.

In the study group there was a significantly higher prevalence of heavy smokers. Tobacco smoking was reported in $49.4 \%$ of study and by $31.0 \%$ of control cases $(P=0.017)$.
There was an even higher difference in smoking more than 60 cigarettes a week ( $30.2 \%$ vs. $14.0 \%, P=0.004$ ). Although the study group revealed a lower proportion of hormone contraception and hormone therapy use $(P<0.001)$, the number of pregnancies and corresponding number of childbirths was significantly lower. More than one third of patients from the study group were never pregnant $(36.0 \%)$ in contrast to $8.0 \%$ women in the control group $(P<0.001)$, and $41.3 \%$ women in study group had not given birth versus $18.0 \%$ in controls $(P<0.001)$.

Almost half of participants in the study group (46.5\%) started their sexual life before the age of 17 in contrast to less than one third $(30.0 \%)$ of women from the control group

Table 1. Characteristics of groups - clinical parameteres.

\begin{tabular}{|c|c|c|c|c|c|}
\hline \multicolumn{2}{|l|}{ Parameters } & Overall & Control group & Study group & $P$ value \\
\hline \multicolumn{2}{|l|}{ Number of patients $(\mathrm{n} ; \%)$} & 272 & $100(36.8)$ & $172(63.2)$ & NA \\
\hline \multicolumn{2}{|l|}{ Age (years) (n; quartils) } & $35.5(23.9 ; 58.3)$ & $37.6(26.2 ; 60.6)$ & $34.2(23.5 ; 56.3)$ & 0.123 \\
\hline \multirow{5}{*}{ Number of pregnancies } & 0 & $70(25.7 \%)$ & $8(8.0 \%)$ & $62(36.0 \%)$ & \multirow{5}{*}{$<0.001$} \\
\hline & 1 & $43(15.8 \%)$ & $15(15.0 \%)$ & $28(16.3 \%)$ & \\
\hline & 2 & $74(27.2 \%)$ & $39(39.0 \%)$ & $35(20.3 \%)$ & \\
\hline & 3 & $43(15.8 \%)$ & $18(18.0 \%)$ & $25(14.5 \%)$ & \\
\hline & $>4$ & $42(15.4 \%)$ & $20(20.0 \%)$ & $22(12.8 \%)$ & \\
\hline \multirow{4}{*}{ Number of childbirths } & 0 & $89(32.7 \%)$ & $18(18.0 \%)$ & $71(41.3 \%)$ & \multirow{4}{*}{$<0.001$} \\
\hline & 1 & $70(25.7 \%)$ & $26(26.0 \%)$ & $44(25.6 \%)$ & \\
\hline & 2 & $86(31.6 \%)$ & $43(43.0 \%)$ & $43(25.0 \%)$ & \\
\hline & 3 or more & $27(9.9 \%)$ & $13(13.0 \%)$ & $14(8.1 \%)$ & \\
\hline \multirow{3}{*}{ Education $^{1)}(\mathrm{n} ; \%)$} & Elementary/apprenticeship & $99(36.4)$ & $35(35.0)$ & $64(37.2)$ & \multirow{3}{*}{0.639} \\
\hline & High school & $125(46.0)$ & $46(46.0)$ & $79(45.9)$ & \\
\hline & University/postgraduate & $47(17.3)$ & $19(19.0)$ & $28(16.3)$ & \\
\hline \multirow{3}{*}{ Smoking (n; \%) } & No smoking in last 6 months & $156(57.4)$ & $69(69.0)$ & $87(50.6)$ & \multirow{3}{*}{0.004} \\
\hline & $1-2$ packs a week & $50(18.4)$ & $17(17.0)$ & $33(19.2)$ & \\
\hline & 3 or more packs a week & $66(24.3)$ & $14(14.0)$ & $52(30.2)$ & \\
\hline \multirow{5}{*}{$\begin{array}{l}\text { Contraception and hormo- } \\
\text { nal therapy (n; \%) }\end{array}$} & Non-user & $151(55.5)$ & $72(72.0)$ & $79(45.9)$ & \multirow{5}{*}{$<0.001$} \\
\hline & $\mathrm{COC}$ & $107(39.3)$ & $22(22.0)$ & $85(49.4)$ & \\
\hline & IUD & $8(2.9)$ & $4(4.0)$ & $4(2.3)$ & \\
\hline & Gestagen contraception & $3(1.1)$ & $0(0.0)$ & $3(1.7)$ & \\
\hline & HRT & $3(1.1)$ & $2(2.0)$ & $1(0.6)$ & \\
\hline \multirow{2}{*}{$\begin{array}{l}\text { History of autoimmune } \\
\text { diseases }(\mathrm{n} ; \%)\end{array}$} & No & $228(83.8)$ & $84(84.0)$ & $144(83.7)$ & \multirow{2}{*}{0.965} \\
\hline & Yes & $44(16.2)$ & $16(16.0)$ & $28(16.3)$ & \\
\hline \multirow{6}{*}{$\begin{array}{l}\text { History of condylomata } \\
\text { acuminata }^{1)}(n ; \%)\end{array}$} & Never & $224(82.4)$ & $79(79.0)$ & $145(84.3)$ & \multirow{6}{*}{0.512} \\
\hline & Never, but partner treated & $36(13.2)$ & $15(15.0)$ & $21(12.2)$ & \\
\hline & $\begin{array}{l}\text { Once treated before last } 6 \text { months, no complication } \\
\text { after treatment }\end{array}$ & $3(1.1)$ & $2(2.0)$ & $1(0.6)$ & \\
\hline & $\begin{array}{l}\text { Once treated within last } 6 \text { months, no complication } \\
\text { after treatment }\end{array}$ & $7(2.6)$ & $4(4.0)$ & $3(1.7)$ & \\
\hline & $\begin{array}{l}\text { Twice or more treated, no complication during } \\
\text { last } 6 \text { months }\end{array}$ & $1(0.4)$ & $0(0.0)$ & $1(0.6)$ & \\
\hline & $\begin{array}{l}\text { Repeatedly treated with long-term or current } \\
\text { complications }\end{array}$ & $0(0.0)$ & $0(0.0)$ & $0(0.0)$ & \\
\hline
\end{tabular}

${ }^{1)}$ Missing value for one patient.

$\mathrm{COC}=$ combined oral contraception; HRT = hormone replacement therapy; IUD = intra-uterine device; NA = not applicable. 
$(P=0.010)$. Only $2.9 \%$ of women from the study group had one lifetime sexual partner in comparison to $9.0 \%$ of women from the control group $(P=0.033)$. Women from the study group more frequently reported a history of anal intercourse (72.0 \% vs. $61.0 \%$; $P=0.008)$. Study group patients also revealed a significantly increased proportion of women who regularly participate in anal sex (38.4\% vs. $24.0 \%)$. Differences between other assessed risk factors including number of sexual partners, frequency of unprotected vaginal coitus, frequency of anal coitus and non-coital contact with anus did not reach statistical significance. Presence of autoimmune diseases was similar in both groups ( $16.3 \%$ vs. $16.0 \% ; P=0.965)$ and also history of condylomata acuminata was not significantly different (3.5 \% vs. $6.0 \% ; P=0.512$ ) (Table 2).

Significantly higher risk of concurrent cervical and anal HPV infection was found between women with sexual noncoital contact with the anus (OR 3.14; 95 \% CI: 1.60, 6.16; $P=$ 0.001). Practicing anal intercourse was less but still significantly more frequent between women with concurrent $\mathrm{HPV}$ infection (OR 1.69; 95 \% CI: 1.05, 2.77; $P=0.042$ ). No other assessed risk factors reached the level of statistical significance (Table 3). Risk factors for multiple anal HPV infection were a history of non-penetrative anal contact (OR 4.92; $95 \%$ CI: $1.57,15.48 ; P=0.006$ ), practicing anal intercourse (OR 3.87; $95 \%$ CI: $1.65,9.05 ; P=0.002)$, more than 5 lifetime sexual partners (OR 2.43; $95 \%$ CI: 1.04, 5.65; $P=0.041$ ), and tobacco use (OR 2.33; $95 \%$ CI: 1.02, 5.43; $P=0.048$ ) (Table 4).

\section{Discussion}

Women with a history of CIN 3 have a nearly five-fold greater risk of developing anal cancer compared to the general population [16-19]. In agreement with this observation, we found a 5.3-fold greater prevalence of anal HPV infection within our study group of "high-risk" women treated for CIN 2+ compared to the control group of "low-risk" women without any significant cervical pathology. Detection of HR HPV DNA in the anus represents potential risk for future malignant transformation, because the majority of anal cancers are caused by HPV infection $[1,2,7,13]$. The main risk factor for development of anal HPV infection is coincident presence of cervical HPV infection. Additionaly the anal cancers share similar risk factors with all HPV-associated cancers, especially cervical cancers [19].

In our cohort, we found simultaneous HPV infection of the cervix and anus in $42.4 \%(73 / 172)$ of women from the study group, while only in $8 \%(8 / 100)$ of patients from the control group. Moreover, the prevalence of anal HPV infection significantly increased with the grade of cervical lesion to $55.5 \%$ in women with microinvasive cervical cancer [16]. Although, the relationship between cervical and anal HPV infections was already demonstrated by previous studies, the concordance of HPV genotypes was reported with a broad spectrum of diversity [20]. Conclusions from the meta-analysis showed, however, dominant (76.6\%)

Table 2. Characteristics of groups - sexual behavior.

\begin{tabular}{|c|c|c|c|c|c|}
\hline Parameters & & Overall & $\begin{array}{l}\text { Control } \\
\text { group }\end{array}$ & Study group & $P$ value \\
\hline \multirow{2}{*}{ Coitarche (age) (n; \%) } & $\leq 17$ & $110(40.4)$ & $30(30.0)$ & $80(46.5)$ & \multirow{2}{*}{0.010} \\
\hline & $>17$ & $162(59.6)$ & $70(70.0)$ & $92(53.5)$ & \\
\hline \multirow{5}{*}{$\begin{array}{l}\text { Number of lifetime sexual } \\
\text { partners }(\mathrm{n} ; \%)\end{array}$} & 1 & $14(5.1)$ & $9(9.0)$ & $5(2.9)$ & \multirow{5}{*}{0.033} \\
\hline & 2 & $28(10.3)$ & $13(13.0)$ & $15(8.7)$ & \\
\hline & $3-5$ & $94(34.6)$ & $33(33.0)$ & $61(35.5)$ & \\
\hline & $6-9$ & $71(26.1)$ & $18(18.0)$ & $53(30.8)$ & \\
\hline & $>10$ & $65(23.9)$ & $27(27.0)$ & $38(22.1)$ & \\
\hline \multirow{6}{*}{$\begin{array}{l}\text { Unprotected vaginal/anal } \\
\text { coitus (n; \%) }\end{array}$} & Never & $15(5.5)$ & $6(6.0)$ & $9(5.2)$ & \multirow{6}{*}{0.499} \\
\hline & Exceptionally with stable partner & $35(12.9)$ & $14(14.0)$ & $21(12.2)$ & \\
\hline & $\begin{array}{l}\text { Never with accidental partner, but exceptionally with } \\
\text { stable partner }\end{array}$ & $13(4.8)$ & $5(5.0)$ & $8(4.7)$ & \\
\hline & Exceptionaly with accidental and stable partner & $15(5.5)$ & $2(2.0)$ & $13(7.6)$ & \\
\hline & $\begin{array}{l}\text { Never with accidental partner, but always with stable } \\
\text { partner }\end{array}$ & $117(43.0)$ & $42(42.0)$ & $75(43.6)$ & \\
\hline & Always & $77(28.3)$ & $31(31.0)$ & $46(26.7)$ & \\
\hline \multirow{3}{*}{$\begin{array}{l}\text { Any sexual contact with } \\
\text { anus }^{1)}(\mathrm{n} ; \%)\end{array}$} & Never & $96(35.3)$ & $33(33.0)$ & $63(36.6)$ & \multirow{3}{*}{0.708} \\
\hline & Exceptionally & $127(46.7)$ & $46(46.0)$ & $81(47.1)$ & \\
\hline & Often/always & $48(17.7)$ & $21(21.0)$ & $27(15.7)$ & \\
\hline \multirow{3}{*}{ Penetrative anal sex (n; \%) } & Never & $177(65.1)$ & $72(72.0)$ & $105(61.0)$ & \multirow{3}{*}{0.008} \\
\hline & Exceptionally & $90(33.1)$ & $24(24.0)$ & $66(38.4)$ & \\
\hline & Often/always & $5(1.8)$ & $4(4.0)$ & $1(0.6)$ & \\
\hline
\end{tabular}

${ }^{11}$ Missing value for one patient. 
Table 3. Risks of concurrent cervical and anal HPV infection.

\begin{tabular}{|c|c|c|c|}
\hline \multicolumn{2}{|l|}{ Factors } & \multirow{2}{*}{$\begin{array}{l}\text { OR }(95 \% \mathrm{CI}) \\
\text { reference group }\end{array}$} & \multirow{2}{*}{$\begin{array}{l}P \text { value } \\
\text { NA }\end{array}$} \\
\hline Education & $\begin{array}{l}\text { Elementary/ } \\
\text { apprenticeship }\end{array}$ & & \\
\hline & High school & $1.22(0.62,2.37)$ & 0.565 \\
\hline & $\begin{array}{l}\text { University/ } \\
\text { postgraduate }\end{array}$ & $0.41(0.18,0.95)$ & 0.045 \\
\hline \multicolumn{2}{|c|}{ Number of pregnancies } & $1.02(0.84,1.24)$ & 0.849 \\
\hline \multicolumn{2}{|l|}{ Number of childbirths } & $0.91(0.68,1.22)$ & 0.534 \\
\hline \multicolumn{2}{|l|}{ User of COC } & $0.97(0.50,1.88)$ & 0.928 \\
\hline \multicolumn{2}{|c|}{ Presence of autoimmune diseases } & $0.90(0.39,2.07)$ & 0.803 \\
\hline \multicolumn{2}{|l|}{ Smoking } & $0.99(0.54,1.82)$ & 0.985 \\
\hline \multicolumn{2}{|c|}{ History of condylomata acuminata } & $0.99(0.42,2.31)$ & 0.980 \\
\hline \multicolumn{2}{|c|}{ Coitarche before age of 17} & $0.91(0.46,1.81)$ & 0.792 \\
\hline \multirow{4}{*}{$\begin{array}{l}\text { Number of sexual } \\
\text { partners }\end{array}$} & $1-2$ & reference group & NA \\
\hline & $3-5$ & $1.15(0.39,3.34)$ & 0.802 \\
\hline & $6-9$ & $1.13(0.38,3.41)$ & 0.824 \\
\hline & $>10$ & $2.11(0.66,6.71)$ & 0.207 \\
\hline \multirow{3}{*}{$\begin{array}{l}\text { Unprotected vaginal/ } \\
\text { anal coitus }\end{array}$} & Never & reference group & NA \\
\hline & Sometimes & $0.48(0.11,2.07)$ & 0.326 \\
\hline & Always & $0.39(0.09,1.75)$ & 0.220 \\
\hline \multirow{3}{*}{$\begin{array}{l}\text { Any sexual contact } \\
\text { with anus }\end{array}$} & Never & reference group & NA \\
\hline & Exceptionally & $2.62(1.28,5.35)$ & 0.008 \\
\hline & Often/always & $1.96(1.02,3.73)$ & 0.049 \\
\hline \multicolumn{2}{|c|}{$\begin{array}{l}\text { Any sexual contact with anus } \\
\text { (exceptionally/often/always) }\end{array}$} & $3.14(1.60,6.16)$ & 0.001 \\
\hline \multicolumn{2}{|l|}{ Penetrative anal sex } & $1.69(1.05,2.77)$ & 0.042 \\
\hline
\end{tabular}

$\mathrm{COC}=$ combined oral contraception; $\mathrm{NA}=$ not applicable.

Table 4. Risks of multiple anal HPV infection.

\begin{tabular}{|c|c|c|c|}
\hline \multicolumn{2}{|l|}{ Factors } & \multirow{2}{*}{$\frac{\mathrm{OR}(95 \% \mathrm{CI})}{\text { reference group }}$} & \multirow{2}{*}{$\frac{P \text { value }}{\text { NA }}$} \\
\hline \multirow{3}{*}{ Education } & Elementary/apprenticeship & & \\
\hline & High school & $0.92(0.38,2.20)$ & 0.849 \\
\hline & University/postgraduate & $0.42(0.11,1.68)$ & 0.222 \\
\hline \multicolumn{2}{|c|}{ Number of pregnancies } & $0.86(0.61,1.20)$ & 0.376 \\
\hline \multicolumn{2}{|c|}{ Number of childbirths } & $0.75(0.44,1.26)$ & 0.272 \\
\hline \multicolumn{2}{|l|}{ User of COC } & $0.58(0.24,1.36)$ & 0.210 \\
\hline \multicolumn{2}{|c|}{ Presence of autoimmune diseases } & $1.02(0.31,3.33)$ & 0.974 \\
\hline \multicolumn{2}{|l|}{ Smoking } & $2.33(1.02,5.43)$ & 0.048 \\
\hline \multicolumn{2}{|c|}{ History of condylomata acuminata } & $0.90(0.28,2.92)$ & 0.864 \\
\hline \multicolumn{2}{|c|}{ Coitarche before age of 17} & $0.69(0.28,1.69)$ & 0.415 \\
\hline \multicolumn{2}{|c|}{ More than 5 sexual lifetime partners } & $2.43(1.04,5.65)$ & 0.041 \\
\hline \multirow{3}{*}{$\begin{array}{l}\text { Unprotected } \\
\text { vaginal/anal } \\
\text { coitus }\end{array}$} & Never & reference group & \\
\hline & Exceptionally & $0.37(0.06,2.27)$ & 0.282 \\
\hline & Always & $0.17(0.02,1.31)$ & 0.089 \\
\hline \multicolumn{2}{|c|}{$\begin{array}{l}\text { Any sexual contact with anus (exceptionally/ } \\
\text { often/always) }\end{array}$} & $4.92(1.57,15.48)$ & 0.006 \\
\hline \multicolumn{2}{|c|}{ Penetrative anal sex } & $3.87(1.65,9.05)$ & 0.002 \\
\hline
\end{tabular}

$\mathrm{COC}=$ combined oral contraception; $\mathrm{NA}=$ not applicable prevalence of HPV 16 in the high-grade anal intraepithelial neoplasia (AIN) [9]. In agreement, we detected concurrent anal HPV 16 infection in $60.4 \%$ of women with CIN 3 and microinvasive cancer.

Significantly elevated risk of anal cancer development in patients with a history of severe cervical pre-cancerous lesion or cervical cancer might be considered a reason for anal HPV testing and repetitive anal Pap smear examination of HPV-positive cases, especially if HPV 16 is detected. Despite the fact that the prevalence of concurrent anal and cervical HPV 16 infection reached nearly two-third of cases in our study, the expected risk of AIN or anal cancers is still relatively low within this subpopulation. Screening examination of all women from this subgroup would not be therefore appropriate and cost effective. One possible strategy is further stratification of this group according to presence of other risk factors. The most relevant factors include risky sexual behaviour, tobacco smoking $[8,10,11,18]$ and alterations of the immune system $[6,20]$. In our study, we did not find any significant association between anal HPV infection and autoimmune disorders. On the other hand, heavy tobacco smoking and some aspects of sexual behaviour were found to be risk factors for concurrent anal HPV infection in women with severe cervical lesions.

Patients from our study group started their sexual life earlier, had more sexual partners and included more than one-third of women who regularly have anal sex. The most important risk factor for concurrent anal HPV infection within this group, however, was any type of sexual contact with the anus including non-penetrative anal sex. Interestingly, a history of receptive anal intercourse was not significantly differently associated with the risk of concurrent anal and cervical HPV infection when compared with a mere anal skin contact during sexual activities. Moreover, all cases with most severe cervical lesions and all cases of anal HPV 16 infections reported any sexual contact with the anus. In contrast with our results, some previous studies did not find any association between anal sex and anal HPV infection in women $[6,14]$. No history of anal intercourse was shown in $44.5 \%(\mathrm{n}=81)$ out of $182 \mathrm{HIV}$ infected and "high-risk" HIV-negative women with concurrent anal and cervical HPV infection [20]. In another study, Park et al. did not demonstrate associations between anal HPV infection and recent or lifetime history of anal sex or number of partners [13]. On the other hand, studies published so far have exclusively evaluated penetrative anal sex, while our results suggest higher importance of alternative routes of transmission, including skin-to-skin contact, oral contact, inoculation by fingers, or vaginal discharge.

In the subgroup of women with proven multiple cervical and anal HPV infection, besides non-penetrative contact with the anus, having more than 5 lifetime sexual partners and a history of anal intercourse were also significant risk factors. A similar association was related to tobacco smoking, especially in women smoking 60 cigarettes per week and 
more. The clinical significance of infection with multiple HPV genotypes is still not well understood [11, 21]. Neveretheless, in men who have sex with men, infection with multiple anal HPV types is often associated with underlying high-grade AIN. Similar data is not, however, available for women $[12,20]$.

In conclusion, a history of severe cervical lesions caused by HR HPV, especially HPV 16, is a strong risk factor for simultaneous anal HPV infection in women. Women with concurrent cervical and anal HPV infections more often reported any type of sexual contact with the anus including non-penetrative anal sex. This observation might suggest higher importance of non-coital routes of transmission. No formal recommendations exist regarding anal cancer screening in women so far. In addition to proposed screening of all HIV-positive women $[21,22]$, our data support anal HPV testing and anal Pap smear screening in cases with severe cervical lesions caused by HPV 16 and a history of any sexual contact with the anus, heavy smoking and/or more than 5 lifetime sexual partners.

Acknowledgements: This study has been supported by the IGA grant no. NT14079-3/2013 and by research project RVOVFN64165 from the Ministry of Health of the Czech Republic, by Charles University in Prague (UNCE 204024) and PRVOUKP27/LF1/1.

\section{References}

[1] SHVETSOV YB, HERNANDEZ BY, MCDUFFIE K, WILKENS LR, ZHU X, NING L et al. Duration and clearance of anal human papillomavirus (HPV) infection among women: the Hawaii HPV cohort study. Clin Infect Dis 2009; 48: 536-46. http://dx.doi.org/10.1086/596758

[2] ABBASAKOOR F, BOULOS PB. Anal intraepithelial neoplasia. Br J Surg 2005; 92: 277-90. http://dx.doi.org/10.1002/ bjs. 4967

[3] ENGELS EA, MADELEINE MM. Invited commentary: Biological and clinical insights from epidemiologic research into HIV, HPV, and anal cancer. Am J Epidemiol 2013; 178: 885-7. http://dx.doi.org/10.1093/aje/kwt149

[4] DONA MG, PALAMARA G, DI CARLO A, LATINI A, VOCATURO A et al. Prevalence, genotype diversity and determinants of anal HPV infection in HIV-uninfected men having sex with men. J Clin Virol 2012; 54: 185-9. http:// dx.doi.org/10.1016/j.jcv.2012.02.014

[5 BERTISCH B, FRANCESCHI S, LISE M, VERNAZZA P, KEISER O et al. Risk factors for anal cancer in persons infected with HIV: a nested case-control study in the Swiss HIV Cohort Study. Am J Epidemiol 2013; 178: 877-84. http://dx.doi. org/10.1093/aje/kwt153

[6] WILLIAMS AB, DARRAGH TM, VRANIZAN K, OCHIA C, MOSS AR AT AL. Anal and cervical human papillomavirus infection and risk of anal and cervical epithelial abnormalities in human immunodeficiency virus-infected women. Obstet Gynecol 1994; 83: 205-11.
[7] JOSEPH DA, MILLER JW, WU X, CHEN VW, MORRIS CR et al. Understanding the burden of human papillomavirusassociated anal cancers in the US. Cancer 2008; 113(10 Suppl): 2892-900.

[8] AMERICAN CANCER SOCIETY. Cancer facts and figures. Atlanta: American Cancer Society 2012.

[9] DE VUYST H, CLIFFORD GM, NASCIMENTO MC, MADELEINE MM, FRANCESCHI S. Prevalence and type distribution of human papillomavirus in carcinoma and intraepithelial neoplasia of the vulva, vagina and anus: a meta-analysis. Int J Cancer 2009; 124: 1626-36. http://dx.doi. org/10.1002/ijc. 24116

[10] DALING JR, MADELEINE MM, JOHNSON LG, SCHWARTZ SM, SHERA KA et al. Human papillomavirus, smoking, and sexual practices in the etiology of anal cancer. Cancer 2004; 101: 270-80. http://dx.doi.org/10.1002/ cncr.20365

[11] FRISCH M, GLIMELIUS B, VAN DEN BRULE AJ, WOHLFAHRT J, MEIJER CJ et al. Sexually transmitted infection as a cause of anal cancer. N Engl J Med 1997; 337: 1350-8. http:// dx.doi.org/10.1056/NEJM199711063371904

[12] HOLLY EA, RALSTON ML, DARRAGH TM, GREENBLATT RM, JAY N et al. Prevalence and risk factors for anal squamous intraepithelial lesions in women. J Natl Cancer Inst 2001; 93: 843-9. http://dx.doi.org/10.1093/ jnci/93.11.843

[13] PARK IU, OGILVIE JW JR, ANDERSON KE, LI ZZ, DARRAH L et al. Anal human papillomavirus infection and abnormal anal cytology in women with genital neoplasia. Gynecol Oncol 2009; 114: 399-403. http://dx.doi. org/10.1016/j.ygyno.2009.05.008

[14] VALARI O, KOLIOPOULOS G, KARAKITSOS P, VALASOULIS G, FOUNTA C et al. Human papillomavirus DNA and mRNA positivity of the anal canal in women with lower genital tract HPV lesions: predictors and clinical implications. Gynecol Oncol 2011; 122: 505-8. http://dx.doi.org/10.1016/j. ygyno.2011.05.033

[15] HERNANDEZ BY, MCDUFFIE K, ZHU X, WILKENS LR, KILLEEN J et al. Anal Human Papillomavirus Infection in Women and Its Relationship with Cervical Infection. Cancer Epidemiol Biomarkers Prev 2005; 14: 2550-6. http://dx.doi. org/10.1158/1055-9965.EPI-05-0460

[16] SEHNAL B, DUSEK L, CIBULA D, ZIMA T, HALASKA M et al. The relationship between the cervical amd anal HPV infection in women with cervical intraepithelial neoplasia. J Clin Virol 2014; 59: 18-23. http://dx.doi.org/10.1016/j. jcv.2013.11.004

[17] OGUNBIYI OA, SCHOLEFIELD JH, ROBERTSON G, SMITH JH, SHARP F et al. Anal human papillomavirus infection and squamous neoplasia in patients with invasive vulvar cancer. Obstet Gynecol 1994; 83: 212-6.

[18] EDGREN G, SPARÉN P. Risk of anogenital cancer after diagnosis of cervical intraepithelial neoplasia. N Engl J Med 1997; 337: 1350-8.

[19] OLSEN JH, MELBYE M. Malignancies that occur before and after anal cancer: clues to their etiology. Am J Epidemiol 1994; 140: 12-9. 
[20] PALEFSKY JM, HOLLY EA, RALSTON ML, DA COSTA M, GREENBLATT RM. Prevalence and risk factors for anal human papillomavirus infection in human immunodeficiency virus (HIV)-positive and high-risk HIV-negative women. J Infect Dis 2001; 183: 383-91. http://dx.doi.org/10.1086/318071

[21] HAYANGA AJ. When to test women for human papillomavirus: take this opportunity to screen for anal cancer too. BMJ 2006; 332: 237. http://dx.doi.org/10.1136/ bmj.332.7535.237-a

[22] CHIN-HONG PV, PALEFSKY JM. Natural history and clinical management of anal human papillomavirus disease in men and women infected with human immunodeficiency virus. Clin Infect Dis 2002; 35: 1127-34. http://dx.doi. org/10.1086/344057 